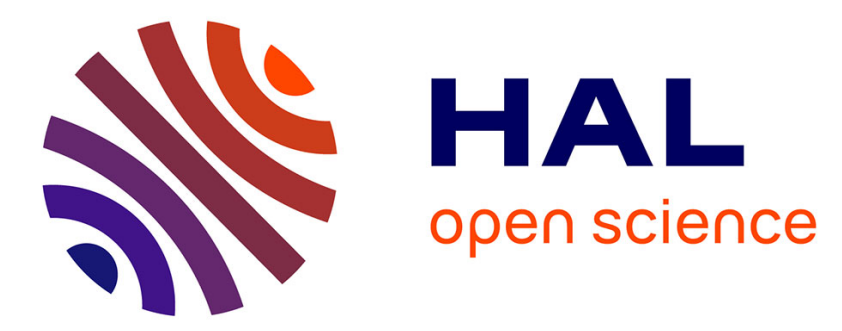

\title{
Damage assessment on buildings using multisensor multimodal very high resolution images and ancillary data
}

\author{
Anne-Lise Chesnel, Renaud Binet, Lucien Wald
}

\section{- To cite this version:}

Anne-Lise Chesnel, Renaud Binet, Lucien Wald. Damage assessment on buildings using multisensor multimodal very high resolution images and ancillary data. 2008 IEEE International Geoscience \& Remote Sensing Symposium (IGARSS 2008), Jul 2008, Boston, Mass., United States. pp.1704, 10.1109/IGARSS.2008.4779585 . hal-00464841

HAL Id: hal-00464841

https: / hal-mines-paristech.archives-ouvertes.fr/hal-00464841

Submitted on 18 Mar 2010

HAL is a multi-disciplinary open access archive for the deposit and dissemination of scientific research documents, whether they are published or not. The documents may come from teaching and research institutions in France or abroad, or from public or private research centers.
L'archive ouverte pluridisciplinaire HAL, est destinée au dépôt et à la diffusion de documents scientifiques de niveau recherche, publiés ou non, émanant des établissements d'enseignement et de recherche français ou étrangers, des laboratoires publics ou privés. 


\section{DAMAGE ASSESSMENT ON BUILDINGS USING MULTISENSOR MULTIMODAL VERY HIGH RESOLUTION IMAGES AND ANCILLARY DATA}

\author{
Anne-Lise Chesnel*, Renaud Binet \\ Commissariat à l'Énergie Atomique \\ Département Analyse et Surveillance de l'Environnement \\ Bruyères-le-Châtel, France \\ annelise.chesnel@gmail.com, renaud.binet@cea.fr
}

\author{
Lucien Wald \\ École des Mines de Paris \\ Centre Energétique et Procédés \\ Sophia-Antipolis, France \\ lucien.wald@ensmp.fr
}

\begin{abstract}
Satellite images are useful to prevent major disasters and mitigate their impact on populations. Their analysis is usually manually conducted by operators. Automatic processing of very high resolution (VHR) images is critical when the images to analyse are acquired with different modalities: acquisition angles, spatial resolution, or even sensor; however, this situation is frequent in an operational scope. We propose a method to assess damage on buildings using a pair of VHR images and ancillary data. We assess its robustness against the different modalities. We show that the performance of our methodology decreases with the acquisition angles difference but is robust against changes in spatial resolution and against the use of images acquired with different sensors. Even in extreme conditions, damaged buildings are well detected. Our methodology leads to a global performance from $72 \%$ with a difference angle of $80^{\circ}$, to $93 \%$ for a difference angle of $24^{\circ}$.
\end{abstract}

Index Terms - Change detection, urban remote sensing, damage assessment, very high resolution images.

\section{INTRODUCTION}

More and more major disasters are reported across the world because their aftermath in terms of human and economical losses are increasing. This increase is explained by the growing population and by its migration in areas that are prone to disasters like seacoasts. Remote sensing has proved its usefulness for the crisis mitigation through situation report and damage assessment, as acknowledged by the creation of the International Charter Space and Major Disaster [1] or initiatives like UNOSAT [2]. In this operational scope, the required information is manually extracted from satellite images. Usually a reference image acquired before the disaster and a crisis image acquired after the disaster are compared to retrieve damage. Damage assessment on buildings is of interest because their collapses lead to most of the human losses. For

\footnotetext{
${ }^{*}$ Corresponding author
}

this purpose, Very High Resolution (VHR) images are usually used because this observation scale allows a more reliable visual analysis. The production of information has to be as short as possible, hence the need of automation to speed it up. The images are to be registered, and this requirement is by fare acute when considering an automatic image analysis method.

On one hand, the crisis image has to be acquired as soon as possible following the disaster, regardless to the acquisition modalities; on the other hand, the reference image has to be as recent as possible, to avoid additional major changes that are not related to damage. Hence there is little chance for the crisis image to be acquired in the same conditions, or even with the same sensor, than the reference image.

Moreover, the multitemporal analysis of VHR images exhibits more natural changes that are not related to damage $[3,4,5,6]$. This is for examples changes due to human activities, or illumination changes. Another major source of changes is the difference in acquisition angles. Theses natural changes have to be corrected or filtered out. Object-oriented methods allow to focus the analysis on the objects of interest, thus to partly avoid false alarms due to natural changes. We focus on the buildings, more precisely on their roofs because they are most often visible by means of remote sensing. For this purpose, we use ancillary data that consist of the buildings roofs outlines in the reference image only. This data can be obtained after a disaster while waiting for the crisis image, by segmentation of the reference image or from a Geographical Information System.

We first describe the images and the ancillary data used as inputs. Then the proposed method to register precisely the buildings roofs is described. The objects of interest being registered, the binary classification of the buildings to detect the damage is conducted and the conclusions are drawn.

\section{INPUT DATA}

The chosen area of study is Beirut, in Lebanon. It is particularly adapted to our study because several images are 
available, before, during and after the bombings in summer 2006. The images set is composed of panchromatic VHR images acquired with two different sensors: two reference images and three crisis images concerning the QuickBird sensor (0.6 $\mathrm{m}$ resolution); two reference images and two crisis images concerning the Ikonos sensor ( $1 \mathrm{~m}$ resolution). Considering monosensor and multisensor pairs, it represents 20 different "reference/crisis" pairs of images. The illumination parameters being different, some related shadows changes are observable in the images (figure 1). The images have also very different acquisition parameters: this difference is represented by the base to height ratio $(\mathrm{B} / \mathrm{H})$ associated to each images pair:

$$
B / H=\sqrt{\left(\frac{\sin a_{2}}{\tan a_{2}}-\frac{\sin a_{1}}{\tan a_{1}}\right)^{2}+\left(\frac{\cos a_{2}}{\tan a_{2}}-\frac{\cos a_{1}}{\tan a_{1}}\right)^{2}},
$$

where $\left(a_{1}, e_{1}\right),\left(a_{2}, e_{2}\right)$ are respectively the azimuth and the elevation of the satellite for the reference and the crisis images.

For our dataset, this $\mathrm{B} / \mathrm{H}$ lies between 0.42 and 1.4 , which is equivalent to a difference angle between $24^{\circ}$ and $80^{\circ}$. The studied urban area includes high buildings, so these differences in acquisition generate large shifts of the roofs from one image to another. These shifts must be compensated to allow a later comparison of the state of the roofs. As often in a crisis context, we do not have any 3-D information about the buildings. We believe more realistic in an operational scope to have 2-D information about the buildings location, thanks to a Geographical Information System, a cadastre or through an image segmentation. Our methodology use as inputs a reference/crisis pair of images, and such a 2-D information as ancillary data.

These ancillary data are the outlines of the buildings roofs, that are manually extracted from only one master QuickBird reference image. Each image (reference and crisis) is rapidly registered to the master reference image according to the ground, using four Ground Control Points (GCPs). Our methodology is applied to the 20 different pairs of images.

The extracts of one of the reference/crisis pairs of images are presented in figure 1. The ancillary data is superimposed on the reference image; the corresponding outlines in terms of geographical coordinates are reported on the crisis image. We observe that a classical registration using GCPs is not enough to precisely register the images. A change detection method can not be applied directly in these conditions. We propose in the next section a method to register the roofs, and thus to allow a damage assessment on the buildings.

\section{FINE BUILDINGS REGISTRATION}

Using the ancillary data in agreement with one reference image, we propose a method that automatically searches for the
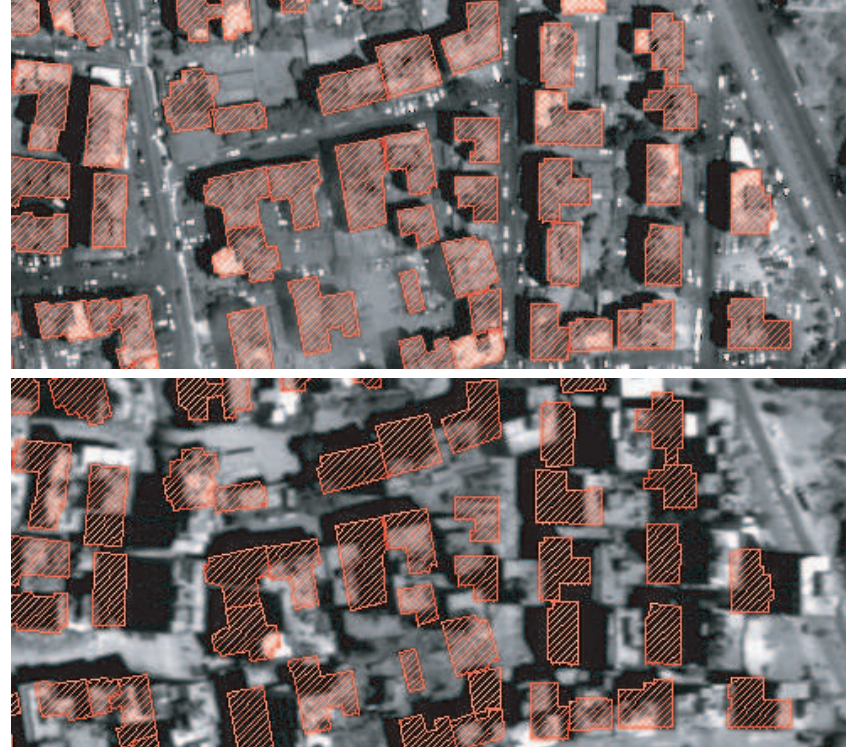

Fig. 1. Extracts of a pair of QuickBird images illustrating the misregistration of the buildings when their height is not compensate during preprocessing. (top): Reference image with buildings outlines (input). (bottom): Crisis image registered to the reference image according to the ground; the buildings outlines from the reference image are reported using their geographical coordinates.

buildings roofs outlines in the other images. This registration is individually conducted for each building, the observed offset being proportional to the $\mathrm{B} / \mathrm{H}$, but also to the building height. The registration method is based on correlation. Classically, such registration method uses a square window for the correlation computation; instead, we propose to use an adaptive window that fits the shape of each roof in the reference image. It aims to maximize the correlation coefficient between the pixels held in the building outline in the reference image and the pixels held in a translated building outline in the crisis image. The correspondence of the building outline is searched in a restricted anisotropic area: the main direction is defined by the epipolar direction, and the length in this direction depends on the $\mathrm{B} / \mathrm{H}$. A small offset in the orthogonal direction is allowed to compensate the ground registration errors. The method is described more precisely in [7].

The result of the building registration corresponding to the extracts of figure 1 is presented in figure 2. We observe that most of the building are correctly registered, despite the large roofs offsets (up to 100 pixels in the epipolar direction).

The registration fails for a few buildings; several reasons can explain this. A large part of the errors are related to destroyed buildings. This is due to the loss of similarity between the state of the building in each image. However, registration for these collapsed buildings has little sense. The other errors are related to buildings occluded by other buildings. This is par- 


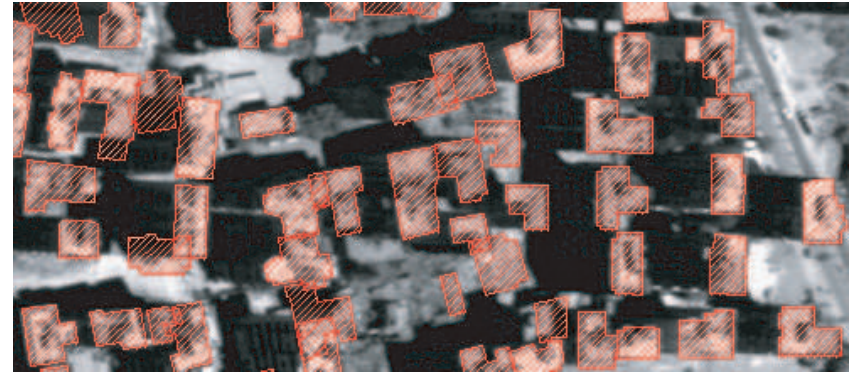

Fig. 2. Result of the fine building registration with the same pair of images. Most of the buildings are well registered; the errors are mainly destroyed and occluded buildings that can not be registered.

ticularly likely when the acquisition incidence angle is high; indeed the images have incidence angle up to $45^{\circ}$. In this case, the building can not be registered. There are some examples in the left part of the figure 2: three outlines do not seem to correspond to any building; the correct location is hidden by nearby higher buildings.

\section{DAMAGE ASSESSMENT AND PERFORMANCE EVALUATION}

The fine registration step allows a comparison of corresponding objects in the images. The evolution of the state of the buildings roofs can be quantified by a change detection method. As we are interested in assigning a damage grade to each building, the correlation coefficients obtained at the end of the registration step can be use to quantify the similarity of the roofs between the two dates. Other change features can be extracted: statistical, textural or morphological features for example.

From this features set, a classification of each building is conducted to decide if it has been damaged or not. Because the features values depend on the images that are processed, a supervised classification is preferred. The drawback of this kind of classification method is that a training set has to be defined for each classification. However, it allows to fit the data with a high confidence level, and thus guaranties the robustness and the applicability of the method to other disasters cases. SVM are chosen for their capability to learn from a small training set, and their rapidity of execution. The classification uses only 10 patterns to classify the totality of the 430 buildings, five for each class. To assess the quality of the classification result, a real damaged grade is assigned to each building through a visual assessment. This real damage grade is compared to the decision of the classifier, and the rate of good classification for all the buildings is evaluated. In the next paragraphs, one investigates the impact of the different modalities of the image acquisition: difference in acquisition angles, spatial resolution and sensors.

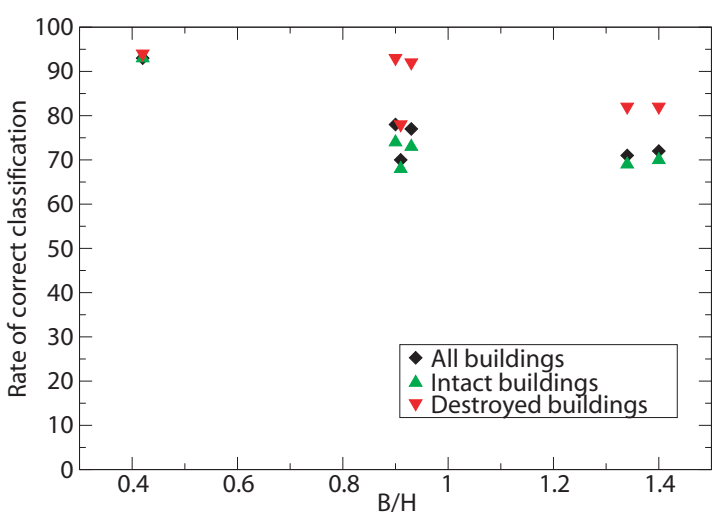

Fig. 3. Damage assessment performances based on QuickBird images pairs as a function of their B/H. 430 buildings are classified (black rhomb) among two classes: intact buildings (green triangles-up) and damaged buildings (red trianglesdown).

\subsection{Images acquisition angles influence}

First, we applied our methodology to the six reference/crisis pairs of QuickBird images. The correlation coefficients obtained between the pixels held in the registered buildings outlines are computed. The classification results using SVM are shown in figure 3 . The results obtained for the totality of the buildings are illustrated along with the specific classification performance for the intact buildings (green triangles-up) and for the damaged buildings (red triangles-down). Whatever the considered damage grade, the classification performance is increasing when the difference in images acquisition angles, represented by the $\mathrm{B} / \mathrm{H}$, decreases. Intact buildings are more affected by this phenomena. However, the method remains robust against extreme difference in acquisition angles. Considering a $\mathrm{B} / \mathrm{H}$ equal to 1.4 , equivalent to a difference angle of $80^{\circ}$, a good classification performance of $72 \%$ is reached; for a $\mathrm{B} / \mathrm{H}$ equal to 0.42 , equivalent to a $24^{\circ}$ angle difference, this performance increases to $93 \%$. The roofs registration is indeed more difficult when the $\mathrm{B} / \mathrm{H}$ is high; however, registration errors only explain a part of the classification errors. The main part of the errors is explained by the geometrical deformations of the buildings roofs when the satellite incidence angles is high. These deformations are due to parallax and make the similarity measure lower. Finally, as it was observed during the specific roofs registration step, occluded buildings are badly classified, because no information is available for them.

\subsection{Images spatial resolution influence}

We investigate the robustness of our method for two different spatial resolutions. For this purpose, we compare the results obtained on one hand from the QuickBird images pairs, and on the other hand from the Ikonos images pairs. The results are shown in figure 4, respectively with the losanges and the 


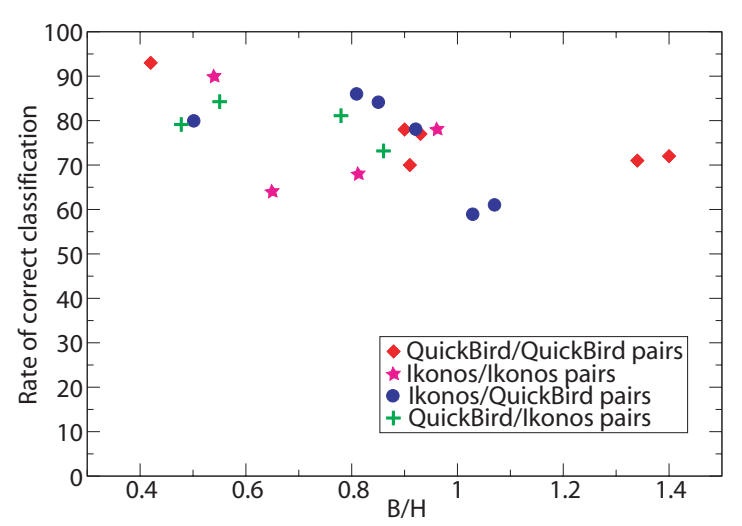

Fig. 4. Damage assessment performances for all images pairs as a function of their $\mathrm{B} / \mathrm{H}$. The monosensor QuickBird images pairs (red losanges) are the results previously presented; the monosensor Ikonos images pairs are represented in purple stars; the multisensors images pairs are presented in blue circles for the Ikonos/QuickBird images and in green crosses for the QuickBird/Ikonos images.

stars. One can see that the Ikonos images pairs lead to results that follow the same trend as with the QuickBird images pairs. We see the same linear decrease of performance along with the $\mathrm{B} / \mathrm{H}$. We conclude that our method gives equivalent results with different very high spatial resolutions. To confirm this conclusion, we have subsampled the QuickBird images to the resolution of the Ikonos one, while keeping the SNR constant. The damage assessment performances from these subsampled images are equal to the ones with the original images, confirming that the proposed method is robust against different spatial resolutions and sensor characteristics.

\subsection{Multisensor images pairs}

Finally, we evaluate the performance of our damage detection method when the reference image is acquired with a different sensor from the crisis image. As explained before, this is a common situation for analysts to use, in a disaster context, images acquired from different sensors. The good classification rates, presented in figure 4 , show the robustness of our method considering multisensor images pairs (circles and crosses): the classification performance increases with decreasing value of $\mathrm{B} / \mathrm{H}$ in the same way as the previous monosensor images pairs.

\section{CONCLUSION}

Damage assessment following a major disaster is often conducted using satellite images. This assessment must be conducted rapidly after the disaster, to help rescue teams and local government. However, the visual analysis of the images is a lengthy work, particularly when the resolution of the images increases.

We propose a damage assessment method based on a semi-automatic analysis of two VHR panchromatic images and some ancillary data that give the buildings outlines in a reference image only. We evaluate the performances of our method against different image acquisition modalities: angles of acquisition (incidence and azimuth angles), spatial resolution, and sensor. We show that the performances remain stable when the spatial resolution varies, and also when the images of the reference/crisis pair are acquired with two different sensors. We demonstrate the impact of a difference in the acquisition angles of the two images: the quality of the results decreases when the two images are acquired with increasing difference angles, but still gives satisfying results. These are promising results for a future operational application, where those difficult analysis conditions are often encountered.

\section{REFERENCES}

[1] International-Charter, "International charter Space and Major Disasters," 2007, Available online at: http://www.disasterscharter.org/.

[2] UNOSAT, "United Nations Institute for Training and Research (UNITAR) Operational Satellite Applications Programme," 2007, Available online at: http://unosat.web.cern.ch/.

[3] B.J. Adams, C.K. Huyck, B. Mansouri, R.T. Eguchi, and M. Shinozuka, "Application of high-resolution optical satellite imagery for post-earthquake damage assessment: The 2003 Boumerdes (Algeria) and Bam (Iran) earthquakes," Research Progress and Accomplishments 20032004, Buffalo: MCEER, 2004.

[4] G. Bitelli, R. Camassi, L. Gusella, and A. Mongnol, "Image change detection on urban area: the earthquake case," in XXth ISPRS Congress, Istanbul, Turkey, July 2004, p. 692.

[5] Z. Chen and T. C. Hutchinson, "Urban damage estimation using statistical processing of satellite images: 2003 Bam, Iran earthquake," Proceedings SPIE, vol. 5667, pp. 289-300, 2005.

[6] M. Sakamoto, Y. Takasago, K. Uto, S. Kakumoto, Y. Kosugi, and T. Doihara, "Automatic detection of damaged area of Iran earthquake by high-resolution satellite imagery," in IEEE Proceedings of International Geoscience and Remote Sensing Symposium 2004, September 2004, vol. 2, pp. 1418-1421.

[7] A.L. Chesnel, R. Binet, and L. Wald, "Quantitative assessment of building damage in urban area using very high resolution images," in Proceedings of the Urban Remote Sensing Joint Event, 2007, April 2007, pp. 1-5. 